\title{
Helmet-Mounted Displays And Facial Injury In US Army AH-64A Apache Accidents
}

\author{
Lt Col JS Crowley \\ MD, Medical Corps, US Army. \\ US Army Exchange Officer
}

Centre for Human Sciences, DERA Farnborough, Hampshire, GU14 6TD.

SUMMARY: There is concern that the helmet display unit (HDU) used by AH-64 Apache helicopter pilots migh contribute to facial injury in a crash. The US Army accident database was searched for HDU-related injuries in survivable Apache accidents 1985-1995. Four aviators in three crashes sustained HDU-related injury. These involveoß three periorbital contusions and two minor eye injuries. There were no sequelae. This equates to an incidence of $0.5 \hat{\mathrm{k}}$ injured individuals per 100,000 flying hours or 8.0 injured aviators per 100 survivable Class A-C accidents in which the HDU was worn. Applying these data to the projected UK Army Apache flying hour programme suggests that oneHDU-related injury might be encountered approximately every 10.1 years. This estimate should be interpreted with $\vec{\omega}$ caution. Serious injury remains a possibility due to the proximity of the HDU to the eye and face.

\section{Introduction}

The procurement of the WAH-64 (Apache) Attack Helicopter by the British Army has generated considerable interest in UK aeromedical circles $(1,2)$. While the Apache has many enhanced safety features (e.g., crashworthy fuel systems, energy-attenuating seats), there are potential safety hazards inherent in its design. Of particular concern is the helmet-mounted display.

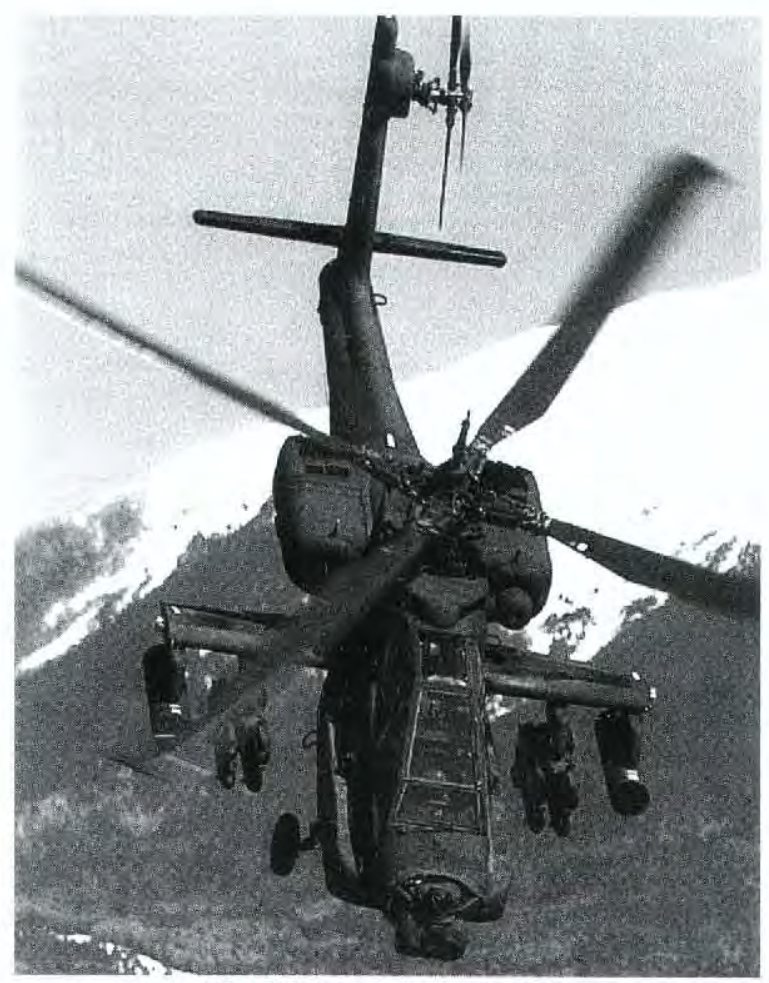

Fig 1. The US Army AH-64A helicopter (US Army photograph).
The AH-64A Apache is a tandem seat, dual engine attack helicopter (Fig 1) that is equipped with an integrated helme $\vec{A}$ and display sighting system (IHADSS) (Figs 2, 3, 4). This

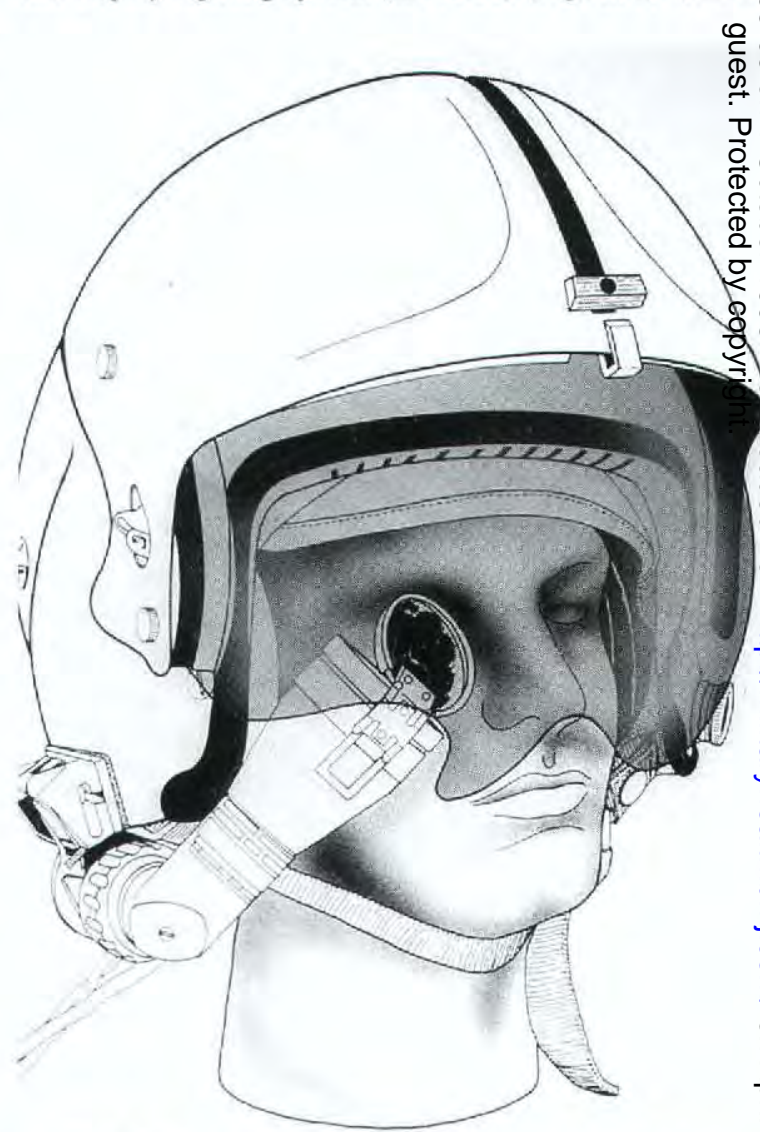

Fig 2. The AH-64 integrated helmet and display sighting system (IHADSS) helmet. Note the proximity $N$ of the HDU to the right side of the aviator's face. 
system provides sensor video and/or symbology to each crewmember via a HDU (Fig 3). The HDU contains a 1inch cathode ray tube (CRT) and attaches to the right side of the helmet, positioning a polycarbonate combiner lens directly in front of the pilot's eye. When in use, the HDU usually rests on the pilot's right cheek; when not needed, it can be rotated away from the face.

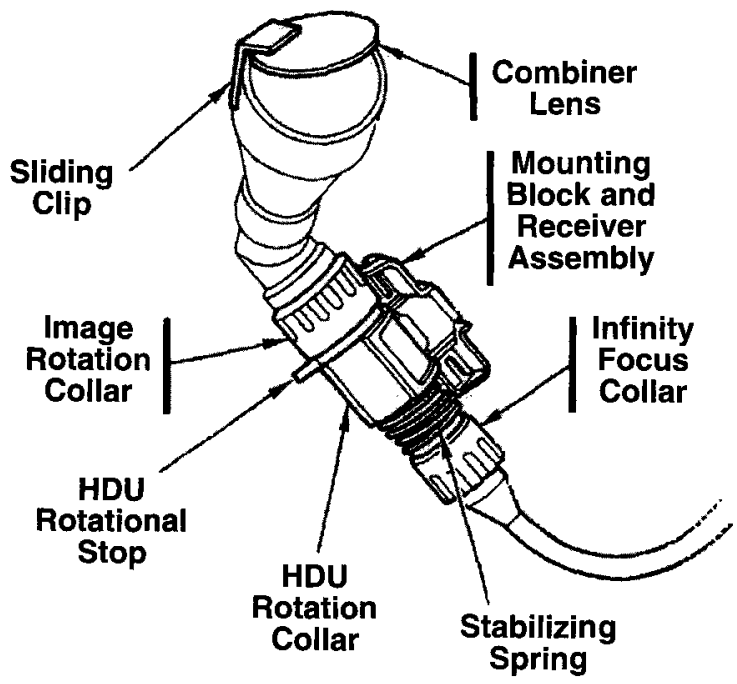

Fig. 3. The AH-64 helmet display unit (HDU) (5).

During a crash sequence, the helicopter pilot is exposed to a variety of potentially lethal forces. Although many injuries are due purely to internal decelerative forces, the most common injury mechanism in US Army helicopter crashes is contact with objects within the cockpit (6). These objects can be divided into two groups: those that are mounted on the aviator's head and those that are attached to the cockpit structure. Examples of the former include the Apache HDU and night vision goggles (NVGs) (7).

These visual aids must be worn extremely close to the aviator's eye(s) and face, constituting a potential injury hazard. The rationale for concern is not that the HDU or NVG will independently cause injury, but rather that in a crash an otherwise blunt impact from a cockpit surface could be focused on critical structures such as the eye or orbit. The HDU combiner lens is made of polycarbonate, so fragmentation is unlikely, but it is positioned at such an angle that orbital injury remains a hazard (Fig. 2). To date no HDU injury analysis has been published.

Since the cockpit environment and HDU design for the WAH-64 helicopter are essentially unchanged from the AH-64A HDU that has been in use for over ten years, a retrospective injury analysis would be relevant to current UK Army concerns. The purpose of this paper is to review the US Army accident experience to determine the incidence of facial injury due to the AH-64A HDU. This information will then be used to predict rates of HDUrelated injury in the UK Attack Helicopter program.
Methods

The US Army Safety Management Information System (ASMIS) computerised database was searched for AH-64 accidents involving injuries related to helmet-mounted 3 displays. The ASMIS database, maintained at the US Army® Safety Center, Fort Rucker, Alabama, is a valuable safety? resource, containing 25 years of detailed accident information. US Army accidents are graded according to cost and injury severity. Current accident classification $\overrightarrow{\overrightarrow{\mathrm{S}}}$ criteria are summarised in Table 1 (8).

Table 1. Current US Army aircraft accident and incident classifications (8).

\begin{tabular}{|l|l|l|}
\hline Accident Class & Property Cost & Injury severity \\
\hline Class A accident & $>\$ 1,000,000$ & $\begin{array}{l}\text { Fatality or permanent total } \\
\text { disability }\end{array}$ \\
\hline Class B accident & $>\$ 200,000$ & $\begin{array}{l}\text { Permanent partial disability } \\
\text { or }>4 \text { days hospitalised. }\end{array}$ \\
\hline Class C accident & $>\$ 10,000$ & Lost-worktime case. \\
\hline Class D accident & $>\$ 2,000$ & $\begin{array}{l}\text { Any other injury requiring } \\
\text { treatment. }\end{array}$ \\
\hline Class E incident & $<\$ 2,000$ & None. \\
\hline
\end{tabular}

Meeting either the criterion cost or the injury severity qualifies an accident for a given class. An $\mathbb{D}$ o accident is also considered Class $A$ if there is total loss $\mathrm{S}$

of an aircraft, regardless of cost. During the study $\vec{D} \overrightarrow{\vec{O}} \overrightarrow{\mathrm{T}}$ period (1988), property cost criteria were adjusted fif inflation. These changes did not affect the outcome of $\overline{0}$ this study.

The database was searched for relevant survivable or partially survivable (hereafter referred to as 'survivable्यु). Class A-C accidents from 1985 to 1995, inclusive, usig several retrieval strategies. First, accidents were sought which an injury had been formally attributed to the HDU. The second search included any accident in which right-气 sided (i.e., the side on which the HDU is worn) facial ${ }^{\mathbb{2}}$ injury occurred to a victim of an AH-64 accident in which $\overrightarrow{\vec{B}}$ an HDU was used. Finally, narrative searches were 3 conducted for the following key words: "helmet display? unit," and "HDU." All accidents meeting search criteria을 were reviewed on-line via ASMIS and irrelevant accidents were discarded. The hard-copy accident reports for the remaining cases were then studied, and a determination made regarding possible HDU injury. Separately, several searches were performed to provide denominator data@ (e.g., number of AH-64 accidents, flight hours, etc.)

\section{Results \\ $H D U$ Injuries}

Only four cases of unambiguous HDU-related injury were found (Table 2), occurring in three accident aircraft.을 These involved three periorbital contusions and two oculard injuries. None of the victims wore spectacles at the time of the accident, although one was wearing contact lenses. No There were no long-term sequelae from any of these injuries, and all four individuals returned to flying. 
Table 2. HDU-related facial injuries.

\begin{tabular}{|c|c|c|c|c|c|}
\hline $\begin{array}{c}\text { Accident } \\
\#\end{array}$ & $\begin{array}{c}\text { Victim } \\
\text { Duty }\end{array}$ & $\begin{array}{c}\text { Body } \\
\text { Region }\end{array}$ & $\begin{array}{c}\text { Injury } \\
\text { Type }\end{array}$ & $\begin{array}{c}\text { Injury } \\
\text { Severity }\end{array}$ & Comments \\
\hline 1 & $\begin{array}{c}\text { Rear } \\
\text { Seat }\end{array}$ & R. cornea & $\begin{array}{c}\text { Laceration/ } \\
\text { abrasion }\end{array}$ & Minor & $\begin{array}{c}\text { Contact lens } \\
\text { dislodged }\end{array}$ \\
\hline 2 & $\begin{array}{c}\text { Rear } \\
\text { Seat }\end{array}$ & $\begin{array}{r}\text { R. superior } \\
\text { eyelid }\end{array}$ & $\begin{array}{c}\text { Contusion } \\
\text { Conimal }\end{array}$ & Minimal & \\
\hline 2 & $\begin{array}{r}\text { Front } \\
\text { Seat }\end{array}$ & $\begin{array}{r}\text { R. superior } \\
\text { and inferior } \\
\text { eyelids }\end{array}$ & Contusion & Minimal & $\begin{array}{c}\text { HDU was } \\
\text { rotated } \\
\text { away at } \\
\text { impact }\end{array}$ \\
\hline 3 & $\begin{array}{r}\text { Front } \\
\text { Seat }\end{array}$ & $\begin{array}{c}\text { R.Sclera } \\
\text { R. Orbit }\end{array}$ & $\begin{array}{c}\text { Haemorrhage } \\
\text { Contusion }\end{array}$ & $\begin{array}{l}\text { Minimal } \\
\text { Minimal }\end{array}$ & \\
\hline
\end{tabular}

Given that there were four individuals injured and 703,666 AH-64A hours flown during the study period, the incidence of an individual suffering an HDU-related facial injury was 0.57 per $100,000 \mathrm{AH}-64 \mathrm{~A}$ flying hours. (While it would be more useful to state the injury rate in terms of hours flown with the HDU in use, these data are not available.)

However, it is possible to state the proportion of accidents occurring while the HDU was in use that involved HDU-related injury. Considering survivable AH64 accidents in which the HDU was used, there were 8 injured aircrew per 100 Class A-C accidents (4/50), and 26.7 per 100 Class A accidents (4/15).

In terms of individual risk of injury, an AH-64 crewmember wearing an HDU had a $4.0 \%$ chance of HDU-related injury if he or she is involved in a survivable Class A-C accident (4/99) and a $13.8 \%$ chance in a survivable Class A accident (4/29). (It was assumed that both crew were wearing the HDU if the accident was coded as involving HDU use, excepting one accident in which the report stated that the co-pilot/gunner was using NVGs.)

\section{Discussion \\ HDU Injuries}

Given the conspicuous proximity of the HDU to the Apache pilot's face, it is surprising that so few attributable injuries were discovered. The reason for this is unknown, but one contributing factor may be the various crashworthy design features incorporated into the Apache that reduce the forces transmitted to the pilot. Another factor might be the "quick release" attachment of the HDU to the flight helmet. That is, the HDU may have already separated by the time the head contacted cockpit structures during the impact sequence. Shannon and Mason recently showed that a similar break-away feature in NVG's is associated with a lower incidence of head and neck injury (9). Additionally, it is possible that some aviators avoided injury by rotating the HDU away from the face to the "stowed" position (note that this does not preclude injury Table 2 . It is also probable that some number of minor facial injuries were unreported, but it is unlikely that any major HDU-related injury in a survivable accident went undiscovered.
Predicting AH injury rates.

The prediction of future accident rates is risky and dependent on many factors. The low number of obserked HDU-related injuries makes these estimates particul unstable. Nonetheless, applying these US Army HळUrelated injury rates to the forecast UK Attack Helicoper programme reveals the following:

Based on a fleet of 58 aircraft, each flying 500 hours/year (personal communication, SJ Durnford, 19 $\overrightarrow{\text { g }}$ ), the annual flying hour programme will be 17,400 houtrs. Applying the US injury rate yields an HDU-related infory rate for the UK of 0.099 injuries per year, or one injübed individual every 10.1 years. This makes the generø̄ assumption that the UK programme will be similar to past US Army Apache flying, especially in terms of accident risk exposure, crash profiles, and the proportion of flỵimg that involves the HDU.

\section{Study Limitations}

This retrospective accident database review may have underestimated injury rates for several reasons. First, there may have been simple errors by investigators, flipht surgeons, data transcribers or computer data entry personnel. For example, two certain HDU-related injufies were coded in the ASMIS computer as being ho्enootrelated. Second, there was a tendency for minor injurregto go unrecorded in victims suffering multiple severe injuries. This can be a major problem for nonsurvof accidents, and may have occurred in severe but survain le accidents as well. For example, a victim with 通席re thoraco-abdominal trauma and extremity amputationsis unlikely to have every minor facial laceration recorde foin the ASMIS computer. Third, inadequate analysis of o.jpiny mechanism by the board flight surgeon frustrated . The analysis in at least one survivable AH-64 acĞdent involving a suspicious head injury. Finally, the assumptorn that both crewmembers were always wearing their HLIs at impact almost certainly exaggerated the numberळof uninjured HDU-users. This would have underestimated individual injury risk by artificially enlarging the denominators.

It is important to note that despite the apparenty reassuring results of this study, serious injury could nno doubt be suffered if the HDU was struck at unfavourable angle. Every accident is different, and the lack of any serious HDU-related injury to date does mot eliminate the hazard or the need for further risk reduction.

\section{Conclusions}

Between 1985 and 1995, inclusive, there were four 预S Army aviators in three AH-64 Apache helicopter cras Q who suffered facial injuries that were definitely ascribed to the HDU. None of these injuries was severe or had ony lasting sequelae.

Based on the US Army accident experience and projected UK Apache flying hour programme, it $N_{i s}$ estimated that one HDU-related facial injury could bुe expected to occur approximately every 10.1 years. TRुis 
estimate depends on a number of assumptions and should be interpreted with caution.

Serious injury remains a possibility due to the proximity of the HDU to the eye and orbit.

\section{Acknowledgments}

Thanks to Ms R Dyson of the US Army Safety Center, Fort Rucker, Alabama, who provided invaluable assistance in retrieving the accident data.

(c) British Crown Copyright 1997/DERA.

Published with the permission of the controller of Her Britannic Majesty's Stationery Office.

This work was supported, in part, by a grant from the Drummond Trust Foundation.

Disclaimer: US Army accident data cannot be used to determine liability in claims against the government; or as evidence to determine pecuniary liability. They are not to be used or introduced as evidence in courts of law. They may be used for safety purposes only and may not be used for any adverse administrative or disciplinary purposes (AR 385-40). The views expressed are those of the author and do not necessarily represent the views of the US Department of Defense.

\section{REFERENCES}

1. STEWART KG. Westland attack helicopter: research topics scoping study. Farnborough, Hampshire: Defence Evaluation and Research Agency. (Unpublished document), 1997.
2. STEwart KG. Westland attack helicopter: selected human factors issues. Farnborough, Hampshire: Defence Evaluation and Research Agency (Unpublished document), 1997.

3. RASH CE, VerONA RW, CROWLEY JS. Human factors and safety considerations of night vision systems flight $\bigcirc$ using thermal imaging systems. Report No. 90-10. Fort응 Rucker, AL: US Army Aeromedical Researchọ Laboratory, 1990.

4. RASH CE, MARTIN JS. The impact of the US Army's? AH-64 helmet mounted display on future aviation? helmet design. Report No. 88-13. Fort Rucker, AL: US음 Army Aeromedical Research Laboratory, 1988.

5. Headquarters, Department of the Army. Operator's $\mathbb{\Phi}$ manual for Army AH-64A helicopter. Washington DC:® Department of the Army, 1984.

6. Shanahan DF, Shanahan MO. Injury in US Army helicopter crashes, FY 1980-85. J. Trauma 1989; $\vec{\omega}$ 29:415-422.

7. VERONA RW, RASH CE. Human factors and safetyg considerations of night vision goggle flight. Report? No. 89-12. Fort Rucker, AL: US Army Aeromedical Research Laboratory, 1989.

8. Headquarters, Department of the Army. Armyc Regulation 385-40: Accident Reporting and Records Washington DC: Department of the Army, 1989.

9. Shannon SG, Mason KT. U.S. Army aviation life support retrieval program: head and neck inju成 among night vision goggle users in rotar wing mishaps. Report No. 98-02. Fort Rucker, Aक्ष:응 US Army Aeromedical Research Laborato 1997.

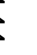

